\title{
Role of Interstitial Fluid Turnover on Target Suppression by Therapeutic Biologics Using a Minimal Physiologically Based Pharmacokinetic Model[ $\mathbb{\$}$
}

\author{
Xiaobing Li, William J. Jusko, and (1) Yanguang Cao
}

\begin{abstract}
Department of Pharmacy, Shengjing Hospital of China Medical University, Shenyang, China (X.L.); Division of Pharmacotherapy and Experimental Therapeutics, UNC Eshelman School of Pharmacy, University of North Carolina at Chapel Hill, Chapel Hill, North Carolina (X.L., Y.C.); and Department of Pharmaceutical Sciences, School of Pharmacy and Pharmaceutical, Sciences, State University of New York at Buffalo, Buffalo, New York (W.J.J.)
\end{abstract}

Received April 23, 2018; accepted July 9, 2018

\begin{abstract}
For therapeutic biologics against soluble ligands, the magnitude and duration of target suppression affect their therapeutic efficacy. Many factors have been evaluated in relation to target suppression but the interstitial fluid turnover rate in target tissues has not been considered. Inspired by the fact that etanercept exerts limited efficacy in Crohn's disease despite its high efficacy in rheumatoid arthritis, we developed a minimal physiologically based pharmacokinetic model to investigate the role of the tissue fluid turnover rate on soluble target suppression and assessed the interrelationships between binding constants and tissue fluid turnover. Interstitial fluid turnover rates in target tissues were found to strongly influence target binding kinetics. For tissues with low fluid turnover, stable binders (low $k_{\text {off }}$ ) exhibit
\end{abstract}

\section{Introduction}

Several therapeutic biologics that neutralize or block soluble proinflammatory cytokine tumor necrosis factor- $\alpha$ (TNF- $\alpha$ ) have demonstrated strong efficacy in the treatment of autoimmune diseases, such as rheumatoid arthritis (RA) and Crohn's disease (CD) (Feldmann et al., 1996; Pizarro and Cominelli, 2007; van Schouwenburg et al., 2013). Monoclonal antibodies (mAbs), such as adalimumab and infliximab and fusion protein etanercept, all exhibit high specificity and affinity for binding to soluble TNF- $\alpha$ and display therapeutic efficacy for RA (Garrison and McDonnell, 1999; Markham and Lamb, 2000; Bang and Keating, 2004). Surprisingly, when using these biologics for $\mathrm{CD}$, another autoimmune disease in which TNF- $\alpha$ is a critical pathogenic factor, only adalimumab and infliximab (but not etanercept) show sufficient efficacy (Olesen et al., 2016). The reason for this difference have focused on the distinct binding affinities of these biologics to transmembrane TNF- $\alpha$ and the role of transmembrane TNF- $\alpha$

This work was supported by the National Institutes of Health National Institute of General Medical Sciences [Grants R35 GM19661 and R01 GM24211]. https://doi.org/10.1124/jpet.118.250134.

S This article has supplemental material available at jpet.aspetjournals.org. greater target suppression, but efficacy is often restricted by accumulation of the drug-target complex. For tissues with high fluid turnover, fast binders (high $k_{\text {on }}$ ) are generally favored, but a plateau effect is present for antibodies with low dissociation rates $\left(k_{\text {off }}\right)$. Etanercept is often regarded as a fast tumor necrosis factor- $\alpha$ (TNF- $\alpha$ ) binder (high $k_{\mathrm{on}}$ ) despite comparable binding affinity $\left(K_{\mathrm{D}}, k_{\text {off }} / k_{\text {on }}\right)$ with adalimumab and infliximab. Crohn's disease largely involves the colon, a tissue with relatively slower fluid turnover than arthritis-associated joint synovium; this may explain why etanercept exerts poor TNF- $\alpha$ suppressive effect in Crohn's disease. This study highlights the importance of tissue interstitial fluid turnover in evaluation of therapeutic antibodies bound to soluble antigens. 
differences in TNF- $\alpha$ binding kinetics and the role of interstitial fluid (ISF) turnover.

For many antibody-based biologics, the interstitial space within the diseased tissues is their actual sites of action. Tissue ISF is generally believed to be the major extravascular distribution space for antibody-based biologics (Cao et al., 2013; Eigenmann et al., 2017). Vascular convection drives antibody distribution into ISF and then lymphatic drainage provides removal from tissue ISF back into the circulation. The efficiency of lymphatic drainage in target tissues, which essentially determines the ISF turnover rate, is expected to affect antibody-target binding kinetics and binding equilibrium, and might further influence the magnitude and duration of target suppression (Guo et al., 2009; Zhou et al., 2011; Becker et al., 2015). The ISF turnover varies greatly among tissues. For antibodies bound to soluble antigens, evaluating the influence of tissue ISF turnover on target suppression and therapeutic efficacy in disease-associated tissues is warranted.

The second-generation minimal physiologically based pharmacokinetic (mPBPK) model accommodates the fundamental distribution mechanisms of mAbs or fusion proteins, such as lymphatic convection and drainage, and ISF as the primary extravascular distribution space (Cao et al., 2013; Cao and Jusko, 2014b). This modeling approach provides a reasonable approximation of antibody concentrations in ISF, and allows incorporating antibody-target binding kinetics in plasma and/or tissue interstitium, or any other disease-associated tissues (Cao and Jusko, 2014a; Chen et al., 2016, 2017). The present assessment extends the original mPBPK model with a specific disease-associated tissue, where the dynamic ISF turnover was defined. The impact of tissue ISF turnover on TNF- $\alpha$ suppression among three TNF- $\alpha$ antagonists (etanercept, adalimumab, and infliximab) was evaluated to test whether the differences of tissue ISF turnover would explain the limited efficacy of etanercept in CD. Antigen binding kinetics in target tissues for biologics with soluble targets was also explored to test the influence of tissue fluid turnover on target binding kinetics and target suppression. This concept was applied to survey 27 licensed antibodies that bind to soluble ligands for various indications and to evaluate how fluid turnover of their target tissues influenced their efficacy.

\section{Materials and Methods}

An Extended mPBPK Model. As shown in Fig. 1, a secondgeneration mPBPK model is proposed with a specific diseaseassociated tissue compartment to assess the impact of tissue ISF turnover on the therapeutic efficacy of biologics that bind to soluble antigens. The mPBPK model is described by the following equations:

$$
\begin{gathered}
\frac{d C_{\mathrm{p}}}{d t}=\frac{L \cdot C_{\text {lymph }}-L_{1} \cdot\left(1-\sigma_{1}\right) \cdot C_{\mathrm{p}}-L_{2} \cdot\left(1-\sigma_{2}\right) \cdot C_{\mathrm{p}}-C_{\mathrm{p}} \cdot C L_{\mathrm{p}}}{V_{\mathrm{p}}} \\
C_{\mathrm{p}}(0)=1000 \mathrm{nM} \\
\frac{d C_{\text {tight }}}{d t}=\frac{L_{1} \cdot\left(1-\sigma_{1}\right) \cdot C_{\mathrm{p}}-L_{1} \cdot\left(1-\sigma_{L}\right) \cdot C_{\text {tight }}}{V_{\text {tight }}} \\
\frac{d C_{\text {leaky }}}{d t}=\frac{L_{2} \cdot\left(1-\sigma_{2}\right) \cdot C_{\mathrm{p}}-L_{2} \cdot\left(1-\sigma_{L}\right) \cdot C_{\text {leaky }}}{V_{\text {leaky }}} \\
\frac{d C_{\text {lymph }}}{d t}=\frac{L_{1} \cdot\left(1-\sigma_{L}\right) \cdot C_{\text {tight }}+L_{2} \cdot\left(1-\sigma_{L}\right) \cdot C_{\text {leaky }}-L \cdot C_{\text {lymph }}}{V_{\text {lymph }}}
\end{gathered}
$$

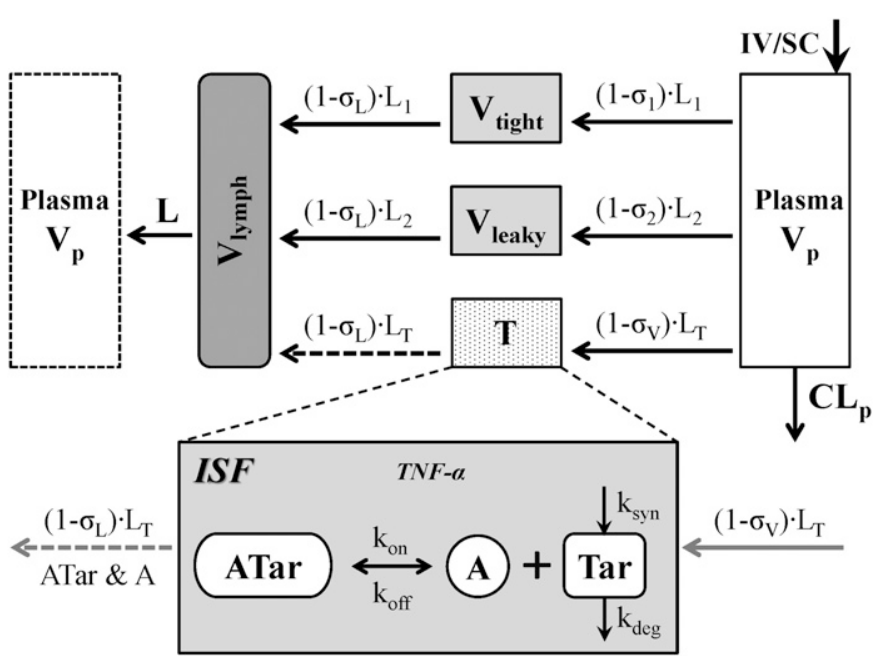

Fig. 1. Second-generation $m P B P K$ model extended with target binding kinetics and ISF turnover in target tissues. The plasma compartment (dashed line) on the left is exactly the same compartment as the plasma compartment on the right. This layout of model structure is consistent with that for full physiologically based pharmacokinetic models. The dashed line of recycled antibody in the target tissue compartment indicates that there is no recycled antibody considered back into the lymph node compartment since the recycled antibody and antibodytarget complex account for only a small fraction of total antibody. Symbols are defined in Table 1 and physiologic restrictions are defined in Eqs. 1-7.

where $C_{p}$ and $C_{\text {lymph }}$ are the mAb concentrations in $V_{\mathrm{p}}$ (plasma volume) and $V_{\text {lymph }}$ (lymph volume), respectively, in a $70 \mathrm{~kg}$ man; $C_{\text {tight }}$ and $C_{\text {leaky }}$ are the mAb ISF concentrations in two groups of lumped tissues categorized by continuous and fenestrated vascular endothelium structures; and $V_{\text {tight }}\left(0.65 \cdot \mathrm{ISF} \cdot K_{\mathrm{p}}\right.$, where ISF is total system ISF and $K_{\mathrm{p}}$ is the available fraction of ISF for distribution) and $V_{\text {leaky }}$ $\left(0.35 \cdot \mathrm{ISF} \cdot K_{\mathrm{p}}\right)$ indicate the ISF volumes for tight tissue (muscle, skin, adipose, and brain) and leaky tissue (all other tissues such as liver, kidney, heart, etc.) (Cao et al., 2013). Here, $L$ is the total lymph flow, which is equal to the sum of $L_{1}$ (lymph flow for $V_{\text {tight }}$ ) and $L_{2}$ (lymph flow for $V_{\text {leaky }}$ ), where $L_{1}=0.33 \times 1$ and $L_{2}=0.67 \times 1$ (Shah and Betts, 2012); $\sigma_{1}$ and $\sigma_{2}$ are the vascular reflection coefficients for $V_{\text {tight }}$ and

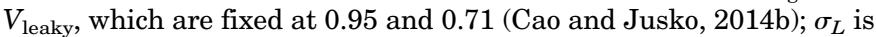
the lymphatic reflection coefficient, which is assumed to be 0.2 in this model (Garg and Balthasar, 2007); and $\mathrm{CL}_{\mathrm{p}}$ is the systemic clearance from plasma (Cao and Jusko, 2014b). All initial conditions equal zero except for $C_{\mathrm{p}}$, which is equal to $1000 \mathrm{nM}$. In this model, the physiologic parameters (Davies and Morris, 1993) for a $70 \mathrm{~kg}$ body weight person are $V_{\mathrm{p}}=2.61, V_{\text {lymph }}=5.21, L=2.9 \mathrm{l} /$ day, $\mathrm{ISF}=15.61$, and $K_{\mathrm{p}}$ was set to 0.8 in this case (Wiig et al., 1994; Wiig and Tenstad, 2001). Here, $C_{\mathrm{p}}$ $(0)=1000 \mathrm{nM}$ was selected within the plasma concentration ranges of many mAbs at their therapeutic doses, which is equivalent to the peak concentrations of antibody in a $70 \mathrm{~kg}$ man after being given about $5 \mathrm{mg} / \mathrm{kg}$ dose of antibody.

Within the target tissue compartment, the target-mediated drug disposition component was defined for the binding kinetics between biologics and soluble TNF- $\alpha$. The differential equations are

$$
\frac{d A}{d t}=C_{\mathrm{p}} \cdot \frac{L_{\mathrm{T}}}{V_{\mathrm{T}}} \cdot\left(1-\sigma_{V}\right)-A \cdot \frac{L_{\mathrm{T}}}{V_{\mathrm{T}}} \cdot\left(1-\sigma_{L}\right)-k_{\mathrm{on}} \cdot A \cdot \operatorname{Tar}+k_{\mathrm{off}} \cdot A \operatorname{Tar}
$$

$$
\begin{gathered}
\frac{d \operatorname{Tar}}{d t}=k_{\mathrm{syn}}-k_{\mathrm{on}} \cdot A \cdot \operatorname{Tar}+k_{\mathrm{off}} \cdot A \operatorname{Tar}-k_{\mathrm{deg}} \cdot \operatorname{Tar} \\
\frac{d A \operatorname{Tar}}{d t}=k_{\mathrm{on}} \cdot A \cdot \operatorname{Tar}-k_{\mathrm{off}} \cdot A \operatorname{Tar}-A \operatorname{Tar} \cdot \frac{L_{T}}{V_{T}} \cdot\left(1-\sigma_{L}\right)
\end{gathered}
$$


where $A$, Tar, and ATar are the concentrations for the antibody, freetarget, and antibody-target complex. Parameters $k_{\text {on }}$ and $k_{\text {off }}$ are the association and dissociation rate constants; $k_{\text {syn }}$ and $k_{\text {deg }}$ represent the target biosynthesis and degradation rates; and Tar $(0)$ is defined as the target baseline $\left(=k_{\mathrm{syn}} / k_{\mathrm{deg}}\right)$. All initial conditions equal zero except for Tar, which equals $100 \%$. The tissue ISF turnover rate was derived from the equation ISF turnover $=L_{T} / V_{T}$, where $L_{T}$ is the lymph flow and $V_{T}$ is the ISF volume for a target tissue. The values for $L_{T}$ and $V_{T}$ are assumed to be $2 \%$ of the system lymph flow and $2 \%$ of the total ISF volume, respectively. All system parameters employed are listed in Table 1.With the binding parameters of etanercept, we simulated a range of tissue ISF turnover (0.001-100 hour ${ }^{-1}$ ), which roughly represented the range of ISF turnover in human tissues. The influence of tissue ISF turnover on concentrations versus time profiles of antibody, free target, and antibody-target complex in target tissues was simulated.

Influence of Tissue ISF Turnover Rate on TNF- $\alpha$ Suppression. The binding kinetic parameters to human soluble TNF- $\alpha$ were obtained from the literature (Kim et al., 2007; Song et al., 2008), where the $k_{\text {on }}$ $\left(\times 10^{5} \mathrm{M}^{-1} \cdot \mathrm{s}^{-1}\right)$ values were $2.59,0.57$, and 1.33 and the $k_{\text {off }}\left(\times 10^{-4} \cdot \mathrm{s}^{-1}\right)$ values were $13.1,1.1$, and 0.73 for etanercept, infliximab, and adalimumab, respectively. All target binding parameters are summarized in Table 2.

The area under the target concentrations $[\operatorname{Tar}(0)-\operatorname{Tar}]$ versus the time curves ( $\Delta$ area under the curve) for the three TNF- $\alpha$ antagonists were simulated with a range of ISF turnover rates, which covered the ranges for the colon (in CD) and joint synovium (in RA). Since the three biologics have different pharmacokinetics characteristics, degrees of tissue distribution, and approved dosing regimens, it is difficult to accurately predict their target site concentration versus time profiles. Previous pharmacokinetics studies suggested that the three biologics may have similar therapeutic concentrations at their maintenance doses (Tracey et al., 2008). Herein, we assumed average antibody pharmacokinetics and tissue distribution kinetics for three biologics (Table 1). This approximation allowed us to specifically evaluate the influence of tissue fluid turnover rate and binding kinetic constants on target suppression. The role of tissue ISF turnover on TNF- $\alpha$ suppression was compared among the three biologics. The TNF- $\alpha$ suppressive effect in two target-associated tissues, joint synovium and colon, was particularly compared.

Interrelationships between Tissue Fluid Turnover and Target-Binding Constants. For a dynamic range of tissue ISF turnover rates $\left(0.001-100\right.$ hour $\left.^{-1}\right)$, we simulated the influence of increasing $k_{\text {on }}$ or decreasing $k_{\text {off }}$, two strategies that could enhance target binding affinity and potentially improve drug efficacy. The impact of binding constants $\left(k_{\text {on }}\right.$ or $k_{\text {off }}$ ) on tissue accumulation of drug-target complexes was also simulated for a dynamic range of ISF turnover rates.
Survey of Licensed Biologics. In the development of therapeutic antibodies, once a viable target is identified a next step is to decide at which degree of binding affinity the antibody could achieve substantial target inhibition. To better understand the relationships between target binding affinity and ISF turnover rates, we surveyed 27 antibodies that have been approved with soluble targets for many types of diseases. The ISF turnover rates of disease-associated tissues were calculated from the equation $L_{\mathrm{T}} / \mathrm{ISF}_{\mathrm{T}}$, where the $L_{\mathrm{T}}$ and $\mathrm{ISF}_{\mathrm{T}}$ values were the lymph flow and ISF volume for specific tissues associated with drug indications collected from the literature (Bauer et al., 1933; Brown et al., 1991; Renkin and Wiig, 1994; Levick, 1998; Shah and Betts, 2012). The biologics adalimumab, belimumab, canakinumab, and infliximab, which have indications associated with multiple indications or tissues, were plotted separately for each indication-corresponding tissue. The ISF turnover rate of tumor is normally low considering the collapsed lymphatic system, which was thus set at 0.0001 hour $^{-1}$. The values of the average binding affinity for each antibody and the ISF turnover rates of their target-associated tissues are listed in Table 2. The parameter $K_{\mathrm{a}}$ was used (reciprocal of $K_{\mathrm{d}}$ and calculated as $k_{\text {on }} / k_{\text {off }}$ ) to reflect the binding affinity. The target turnover values for each target in Table 2 are listed in Supplemental Table 1.

Simulation and Statistical Analysis. Model simulations were performed using Berkeley Madonna (version 8.3.18; Berkeley Madonna Inc., University of California, Berkeley, CA). All of the graphs and the statistical analysis were performed using GraphPad Prism 6 software (San Diego, CA). The values on the plots are expressed as mean \pm S.D.

\section{Results}

Influence of Tissue ISF Turnover on Target Binding Kinetics. To evaluate the influence of tissue ISF turnover rate on antibody-target binding kinetics, tissue concentration versus time profiles of antibody, free-target, and antibodytarget binding complex for different ISF turnover rates from 0.001 to 100 hour $^{-1}$ were simulated (Fig. 2). When the ISF turnover rate is decreased from 100 to 0.001 hour $^{-1}$, the amount of antibody that distributes into the target tissues becomes restricted, since lymphatic convection primarily determines antibody access into disease tissues (Fig. 2A). The distribution rate also becomes slower with a decrease in the tissue ISF turnover rate. Tissues with higher ISF turnover rates generally experience stronger target suppression (Fig. 2B), which is partly associated with greater antibody concentrations in these tissues (Fig. 2A). This is also largely ascribed to

TABLE 1

Model parameters employed in the extended mPBPK model simulations

\begin{tabular}{lllll}
\hline Parameter & \multicolumn{1}{c}{ Definition } & Value & Unit & \multicolumn{1}{c}{ Reference } \\
\hline$\sigma_{1}$ & Vascular reflection coefficient for tight tissue & 0.95 & - & Cao and Jusko (2014b) \\
$\sigma_{2}$ & Vascular reflection coefficient for leaky tissue & 0.71 & - & Cao and Jusko (2014b) \\
$\sigma_{L}$ & Lymphatic reflection coefficient & 0.20 & - & Garg and Balthasar (2007) \\
$\sigma_{V}$ & Vascular reflection coefficient for target tissue & 0.50 & - & Cao and Jusko (2014a) \\
$L$ & Total lymph flow & $2.9 / 24$ & $\mathrm{l} \cdot \mathrm{h}^{-1}$ & Lindena et al. (1986) \\
$L_{1}$ & Lymph flow for tight tissue & 0.0399 & $\mathrm{l} \cdot \mathrm{h}^{-1}$ & Shah and Betts (2012) \\
$L_{2}$ & Lymph flow for leaky tissue & 0.081 & $\mathrm{l} \cdot \mathrm{h}^{-1}$ & Shah and Betts (2012) \\
$\mathrm{CL}_{\mathrm{p}}$ & Systemic clearance & 0.01 & $\mathrm{l} \cdot \mathrm{h}^{-1}$ & Cao and Jusko (2014b) \\
$L_{\mathrm{T}}$ & Lymph flow for target tissue (2\% of total) & 0.00242 & $\mathrm{l} \cdot \mathrm{h}^{-1}$ & Davies and Morris (1993) \\
$V_{\text {tight }}$ & ISF for tight tissue & 8.112 & $\mathrm{l}$ & Cao and Jusko (2014a) \\
$V_{\text {leaky }}$ & ISF for leaky tissue & 4.368 & $\mathrm{l}$ & Cao and Jusko (2014a) \\
$V_{\mathrm{T}}$ & ISF for target tissue (2\% of total ISF) & 0.314 & $\mathrm{l}$ & Davies and Morris (1993) \\
$V_{\mathrm{lymph}}$ & Lymph volume & 5.2 & $\mathrm{l}$ Davies and Morris (1993) \\
$V_{\mathrm{p}}$ & Plasma volume & 2.6 & $\mathrm{l}$ & Davies and Morris (1993) \\
$k_{\mathrm{deg}}$ & Free target degradation rate & 4.2 & $\mathrm{~h}$ & Cao and Jusko (2014a) \\
$k_{\mathrm{syn}}$ & Target biosynthesis rate in target tissue & 4.2 & $\mathrm{nM} \cdot \mathrm{h}^{-1}$ & Cao and Jusko (2014a) \\
\hline
\end{tabular}


TABLE 2

Properties related to 27 surveyed therapeutic antibodies

\begin{tabular}{|c|c|c|c|c|c|}
\hline Antibody & Average $K_{D}$ & Target & Target Tissue & ISF Turnover & Reference $^{a}$ \\
\hline & $n M$ & & & $h^{-1}$ & \\
\hline Bevacizumab & 1.10 & VEGF & Tumor & 0.0001 & Carter (2006) \\
\hline Romosozumab & 0.01 & Sclerostin & Bone & 0.003 & Chouinard et al. (2016) \\
\hline Eculizumab & 0.12 & $\mathrm{C} 5$ & Muscle & 0.007 & Rother et al. (2007) \\
\hline Belimumab & 0.20 & BAFF & Whole body & 0.0077 & Zhou and Theil (2015) \\
\hline Ranibizumab & 0.046 & VEGF & Whole body & 0.0077 & Platania et al. (2015) \\
\hline Adalimumab & 0.55 & TNF- $\alpha$ & Colon & 0.04 & Song et al. (2008) \\
\hline Bezlotoxumab & 0.75 & Clostridium difficile & Colon & 0.04 & Hernandez et al. (2015) \\
\hline $\begin{array}{l}\text { Infliximab } \\
\text { lima }\end{array}$ & 1.92 & TNF- $\alpha$ & Colon & 0.04 & Kim et al. (2007) \\
\hline Brodalumab & 0.239 & IL-17RA & Skin & 0.05 & Greig (2016) \\
\hline Ixekizumab & 0.0018 & IL-17A & Skin & 0.05 & Liu et al. (2016) \\
\hline Secukinumab & 0.166 & IL-17A & Skin & 0.05 & Beerli et al. (2014) \\
\hline Ustekinumab & 0.10 & IL-12, IL-23 & Skin & 0.05 & De Luca and Trifonova (2017) \\
\hline Adalimumab & 0.55 & TNF- $\alpha$ & Joint synovium & 0.15 & Song et al. (2008) \\
\hline Canakinumab & 0.031 & IL-1 $\beta$ & Joint synovium & 0.15 & Rondeau et al. (2015) \\
\hline Certolizumab Pegol & 0.09 & TNF- $\alpha$ & Joint synovium & 0.15 & Patel and Moreland (2010) \\
\hline Etanercept & 5.10 & TNF- $\alpha$ & Joint synovium & 0.15 & Kim et al. (2007) \\
\hline Golimumab & 0.018 & TNF- $\alpha$ & Joint synovium & 0.15 & Shealy et al. (2010) \\
\hline Infliximab & 1.92 & TNF- $\alpha$ & Joint synovium & 0.15 & Kim et al. (2007) \\
\hline Mavrilimumab & 0.103 & GM-CSF & Joint synovium & 0.15 & Wang et al. (2018) \\
\hline Mepolizumab & 0.0042 & IL-5 & Lung & 1.21 & Hart et al. (2001) \\
\hline Obiltoxaximab & 0.33 & Bacillus anthracis & Lung & 1.21 & Nagy et al. (2017) \\
\hline Omalizumab & 0.17 & $\mathrm{IgE}$ & Lung & 1.21 & Carter (2006) \\
\hline Raxibacumab & 2.78 & Anthrax toxin & Lung & 1.21 & Mazumdar (2009) \\
\hline Reslizumab & 0.02 & IL-5 & Lung & 1.21 & Amini-Vaughan et al. (2012) \\
\hline Canakinumab & 0.031 & IL- $1 \beta$ & Kidney & 1.46 & Rondeau et al. (2015) \\
\hline Siltuximab & 0.034 & IL-6 & Lymph node & 7.91 & Deisseroth et al. (2015) \\
\hline Abciximab & 5.00 & GPIIb/IIIa & Plasma & 58.19 & Carter (2006) \\
\hline Alirocumab & 0.58 & $\begin{array}{l}\text { PCSK9 } \\
\text { PCS }\end{array}$ & Plasma & 58.19 & Poirier and Mayer (2013) \\
\hline Belimumab & 0.2 & BAFF & Plasma & 58.19 & Zhou and Theil (2015) \\
\hline Evolocumab & 0.008 & PCSK9 & Plasma & 58.19 & Gibbs et al. (2017) \\
\hline Idarucizumab & 0.002 & Dabigatran & Plasma & 58.19 & Eikelboom et al. (2015) \\
\hline
\end{tabular}

increased efficiency in removing antibody-target complexes from these tissues through fast lymphatic flow; efficient removal of complexes drive target binding kinetics toward complex formation (i.e., association). As shown in Fig. 2C, an antibody-target complex gradually accumulates with a decrease in the ISF turnover rate from 100 to 0.1 hour $^{-1}$ Greater accumulation of a drug-target complex would disturb the binding equilibrium and drive complex dissociation. Once tissue ISF turnover becomes lower than 0.1 hour $^{-1}$, the drug-target complex would start to decrease since there would be insufficient tissue antibodies for binding to the target.

Influence of Tissue ISF Turnover Rates on TNF- $\alpha$ Suppression. Compared with infliximab and adalimumab, etanercept is generally regarded as a fast $\mathrm{TNF}-\alpha$ binder since it exhibits a higher association rate $\left(k_{\text {on }}\right.$ is 2 - to 5 -fold higher). In contrast, infliximab and adalimumab are regarded as stable TNF- $\alpha$ binders since they both have relatively lower dissociation rates $\left(k_{\text {off }}\right.$ is much slower than that for etanercept). With such distinct binding kinetics, their TNF- $\alpha$ suppressive effects ( $\Delta$ area under the curve) in target tissues with changing ISF turnover are shown in Fig. 3. For target tissues with relatively slow ISF turnover rate, i.e., shown on the left-hand side in Fig. 3, infliximab and adalimumab show higher TNF- $\alpha$ suppressive effects. Considering that infliximab and adalimumab are both able to form large immune complexes, their effective dissociation rates are even lower than that at 1:1 binding (Scallon et al., 2002). Thus, the actual TNF- $\alpha$ suppressive effects for infliximab and adalimumab are expected to be greater than what is shown in Fig. 3. Such large immune complexes are seldom observed during etanercept treatment, which would not improve its poor TNF- $\alpha$ suppressive effects in tissue with low fluid turnover. However, along with the increase in tissue ISF turnover, the target suppressive effect of etanercept gradually increases and even surpasses infliximab once the tissue ISF turnover rate is $>1$ hour $^{-1}$.

Two target tissues, colon (for CD) and joint synovium (for RA) are shown in Fig. 3 with their reported ISF turnover rates (0.03-0.06 for colon and 0.15-1.0 hour $^{-1}$ for joint synovium). In the colon, two stable binders, infliximab and adalimumab, are expected to exhibit much higher target suppression than the fast binder etanercept. In joint synovium, differences in target suppression become smaller, and etanercept may potentially exhibit even greater TNF- $\alpha$ suppression than infliximab. This simulation provides a theoretical explanation for the limited efficacy of etanercept in CD, even though all three biologics showed comparable efficacy in RA at their therapeutic doses.

Interrelationships between Tissue Fluid Turnover and Target-Binding Constants. Optimization of the targetbinding constants $\left(k_{\text {on }}\right.$ and $k_{\text {off }}$ ) is a critical step in the development of therapeutic antibodies. Here, we simulated the potential effect of altering the target-binding constants on target suppression for tissues with a dynamic range of ISF turnover rates. As shown in Fig. 4A, a gradual increase in $k_{\text {on }}$ produces greater target suppression, and there seems to be no capacity limitation in the simulated range, particularly in 


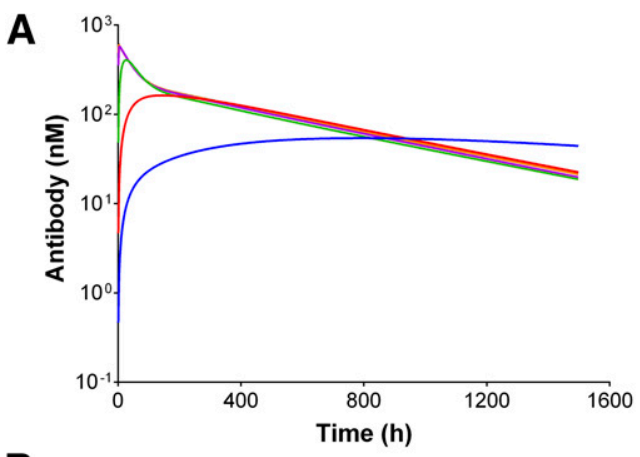

B

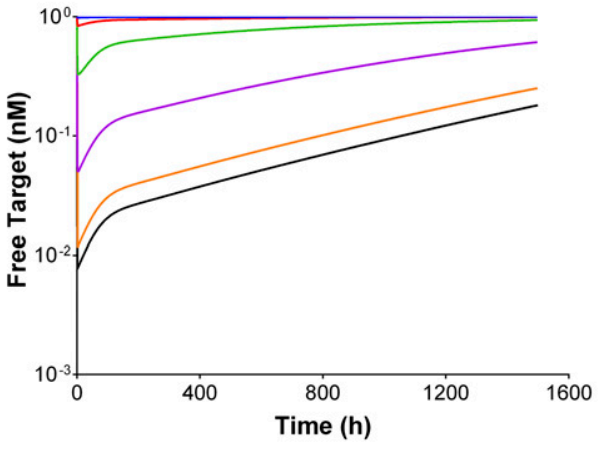

ISF turnover $\left(\mathbf{h}^{-1}\right)$

$-0.001$

$-0.01$

$-0.1$

$-1$

$-10$

$-100$

C

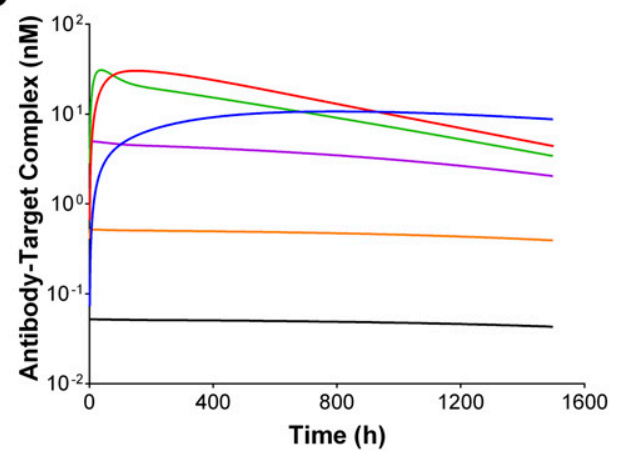

Fig. 2. Simulated target tissue concentration vs. time profiles of free antibody (A), free target (B), and antibody-target binding complex (C) at a dynamic range of tissue ISF turnover rates from 0.001 to 100 hour $^{-1}$. Tissue ISF turnover rates greatly influence target binding kinetics. Tissues with high fluid turnover are expected to have higher target suppression, which is partly ascribed to increased distribution of antibody and high efficiency in removal of drug-target complexes.

tissues with higher ISF turnover. On the other hand, a decrease in $k_{\text {off }}$ (Fig. 4B), a commonly applied engineering strategy, showed a saturation effect in target suppression. This saturation was particularly apparent in tissues with relatively high ISF turnover rates.

As shown in Fig. 4, C and D, there is considerable accumulation of drug-target complexes in tissues with relatively slow ISF turnover rates. Stronger binding affinity produces increased accumulation of the drug-receptor complex. The increased complex accumulation in tissues with slow ISF turnover rates accounts for their lower target suppression (Fig. 4, A and B).

Four Scenarios Defined by Target Binding Affinity and Tissue ISF Turnover. Considering that the tissue ISF turnover rate and target binding affinity both affect target inhibition, herein we have defined four general scenarios based on the following criteria: high ISF turnover rate $\left(>0.0077 \mathrm{hour}^{-1}\right.$, the system average) and high target affinity $\left(>1 \mathrm{nM}^{-1}\right)$; high ISF turnover rate and low target affinity $\left(<1 \mathrm{nM}^{-1}\right)$; low ISF

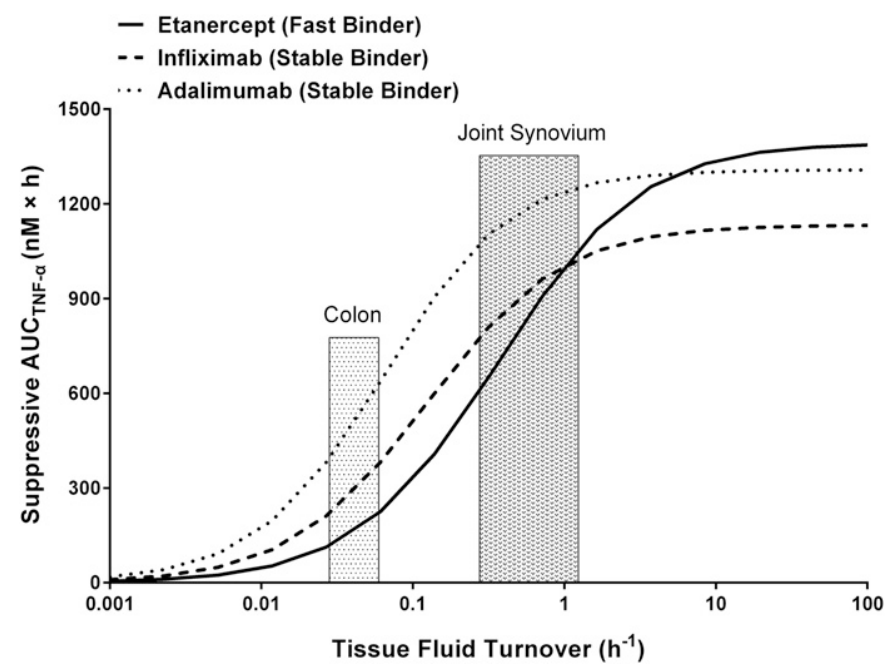

Fig. 3. Simulated interrelationships between tissue fluid turnover rate and the TNF- $\alpha$ suppressive effects $[\Delta$ area under the curve (AUC)] by three anti-TNF- $\alpha$ biologics at a dynamic range of tissue ISF turnover rates. Simulation was performed using the binding constants (see Table 1) of each biologic to soluble TNF- $\alpha$ at their therapeutic doses. For joint (in RA), etanercept shows comparable or slightly higher target suppression than adalimumab and inflixiamb. However, for colon (in CD), etanercept exhibits much less target suppression than the other two biologics.

turnover rate and high target affinity $\left(>1 \mathrm{nM}^{-1}\right)$; and low ISF turnover rate and low target affinity $\left(<1 \mathrm{nM}^{-1}\right)$.

These scenarios are shown in Fig. 5A. For tissues with high ISF turnover rates, fast target binders are favored for target inhibition, as indicated in Figs. 3 and 4A. However, there would be a plateau effect at high affinity by lowering $k_{\text {off }}$ (Fig. $4 \mathrm{~B}$ ). For tissues with relatively low ISF turnover rates, on average the target suppressive effect would be weaker than for tissues with high ISF turnover rates (Fig. 2B; Fig. 3), where stable binders are generally favored for therapy. Decreasing $k_{\text {off }}$ is expected to be more efficacious than increasing $k_{\text {on }}$ to improve target suppression in tissues with low ISF turnover rates. However, both strategies encounter the problem of accumulation of drug-target complexes, which could shift the binding equilibrium toward complex dissociation (Fig. 4, C and D). To effectively enhance target suppression for tissues with slow ISF turnover rates, reduction of complex accumulation should be considered as a therapeutic strategy.

Surveyed Licensed Biologics. For the 27 surveyed biologics, the average target binding affinity and the ISF turnover rates of their corresponding disease tissues are summarized in Table 2 and Fig. 5B. Based on the scenarios shown in Fig. 5A, whole body turnover, calculated from the ratio of the total body flow rate and systemic ISF volume $\left(L / \mathrm{ISF}=0.0077\right.$ hour $\left.^{-1}\right)$, is defined as the system average turnover rate and is used to demarcate tissues into two scenarios: low-turnover tissues (tumor, bone, and muscle) and high-turnover tissues (colon, skin, joint, lung, kidney, lymph node, and plasma). As shown in Fig. 5B, 24 out of $27(\sim 90 \%)$ approved biologics are associated with diseases in tissues with high ISF turnover rates. In those tissues with high ISF turnover rates, fast binders with adequate target binding affinities are expected to achieve high target suppression and sufficient therapeutic efficacy. Antibody candidates with fast binding constants thus have a higher possibility of therapeutic success. 
A

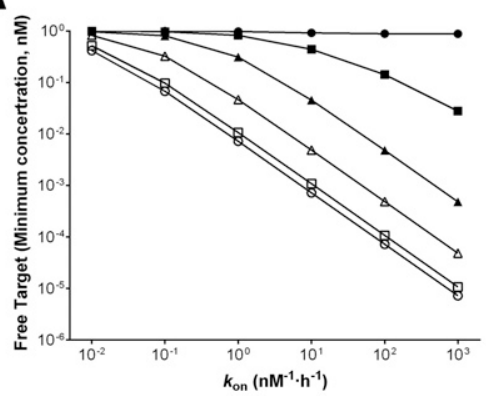

B

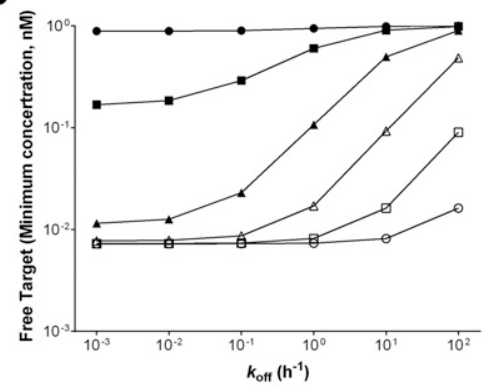

C

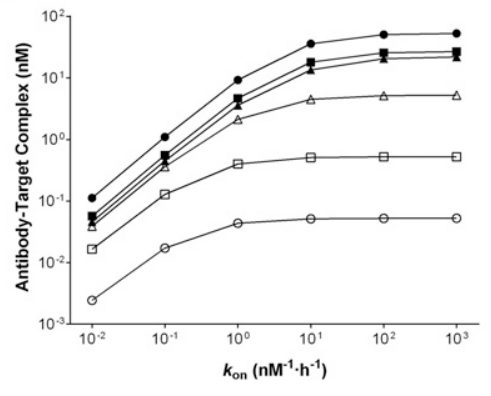

D

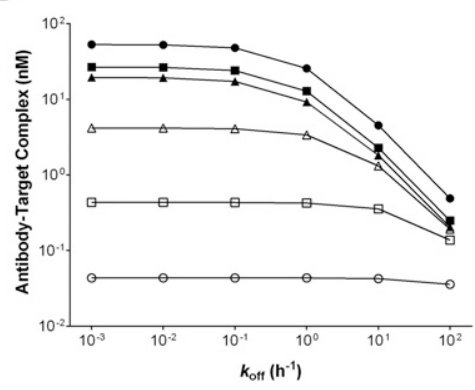

ISF turnover

$\left(\mathrm{h}^{-1}\right)$

- 0.001

$-0.01$

$\mp 0.1$

$\triangle 1$

Ð 10

$\theta 100$
Fig. 4. Influence of changing antibodytarget binding kinetics $\left(k_{\text {on }}\right.$ and $\left.k_{\text {off }}\right)$ for a dynamic range of tissue ISF turnover rates on minimum concentrations of free target (A and B) and accumulation of antibodytarget complex $(\mathrm{C}$ and $\mathrm{D})$. There is a plateau effect by lowering $k_{\text {off }}$ to improve binding affinity, particularly for tissues with relatively slow ISF turnover rates.

\section{Discussion}

Many therapeutic biologics, such as mAbs and infusion proteins, have been developed to neutralize soluble pathogenic ligands in disease-associated tissues (Wang et al., 2016). For those biologics, the magnitude and duration of target neutralization largely predicts their therapeutic efficacy. Optimization of antibody-target binding constants is an essential strategy to improve therapeutic efficacy (Stein and Ramakrishna, 2017; Tiwari et al., 2017). Inspired by the distinct efficacy of three anti-TNF- $\alpha$ biologics (adalimumab, infliximab, and etanercept) for CD, we used an extended mPBPK model to evaluate the influence of tissue ISF turnover rates on target suppression for biologics that neutralize soluble targets. The different TNF- $\alpha$ suppression effects of the three biologics were simulated at a dynamic range of tissue fluid turnover rates. Even though these biologics exhibit comparable TNF- $\alpha$ binding affinity at the subnanomolar range, adalimumab and infliximab are considered to be stable binders because of their relatively lower $k_{\text {on }}$ and $k_{\text {off }}$ values to soluble TNF- $\alpha$ compared with etanercept. These two stable binders were predicted to have greater target suppression than etanercept in the CD-site colon. On the other hand, etanercept is expected to have comparable or a slightly stronger TNF- $\alpha$ suppression than adalimumab and infliximab at the RA-site joint synovium. Therefore, the different tissue fluid turnover rates between the colon and joint synovium may explain why etanercept exhibits limited efficacy in CD.

In this study, an mPBPK model with target-mediated drug disposition in a target tissue compartment was developed to demonstrate the importance of tissue fluid turnover rates on the magnitude of target suppression. In the model, tissue degradation of the target-antibody complex was assumed negligible and the antibody-target complex exhibited similar disposition behavior as free antibody (Tiwari et al., 2017). In the developed model, the volume of ISF in the target tissue was assumed to be $2 \%$ of the total ISF (with the lymph flow being about $2 \%$ of the total lymph flow), which makes the amount of antibody contained in the target tissue not a significant factor in the system mass balance. For simplicity, the recycled antibody was not considered in the plasma compartment. In addition, the Fc-mediated nonspecific clearance pathway was not separately defined in the model since it was included as part of the total linear clearance.

For biologics binding to soluble targets, the ISF turnover rate in disease-associated tissues considerably influenced the magnitude and duration of target suppression. Tissue fluid turnover rates were thus systematically assessed as a critical factor for target suppression. As shown in our analysis, the tissue fluid turnover rate not only determines the tissue concentrations of antibody, but also affects the removal efficiency and accumulation of antibody-target complexes in disease-associated tissue. The latter limits the effect of biologics in suppression of soluble targets. On the other hand, for tissues with relatively fast fluid turnover, a ceiling effect was observed when decreasing dissociation rates beyond target tissue fluid turnover rates in seeking to increase binding affinity and further improve therapeutic efficacy. This concept is summarized in Fig. 5. For example, in the joint synovium, a tissue with fast fluid turnover, a fast binder (high $k_{\text {on }}$ ) rather than a stable binder (low $k_{\text {off }}$ ) is favored for improved target suppression. Target suppression cannot be increased when lowering $k_{\text {off }}$ beyond the fluid turnover rate. There is no numerical cutoff of $k_{\text {on }}$ and $k_{\text {off }}$ values for a given antibody to make it a faster or stable binder since it is dependent on the fluid turnover rates in the target tissues. Fast binders should be antibodies that have high $k_{\text {on }}$ values to allow the antibody and target to sufficiently bind during the fluid turnover process of their target tissues. Stable binders should be antibodies that have low $k_{\text {off }}$ values to keep the antibody-target complex during tissue fluid turnover. These findings have implications for prioritizing strategies in the development of biologics for soluble targets in tissues. 

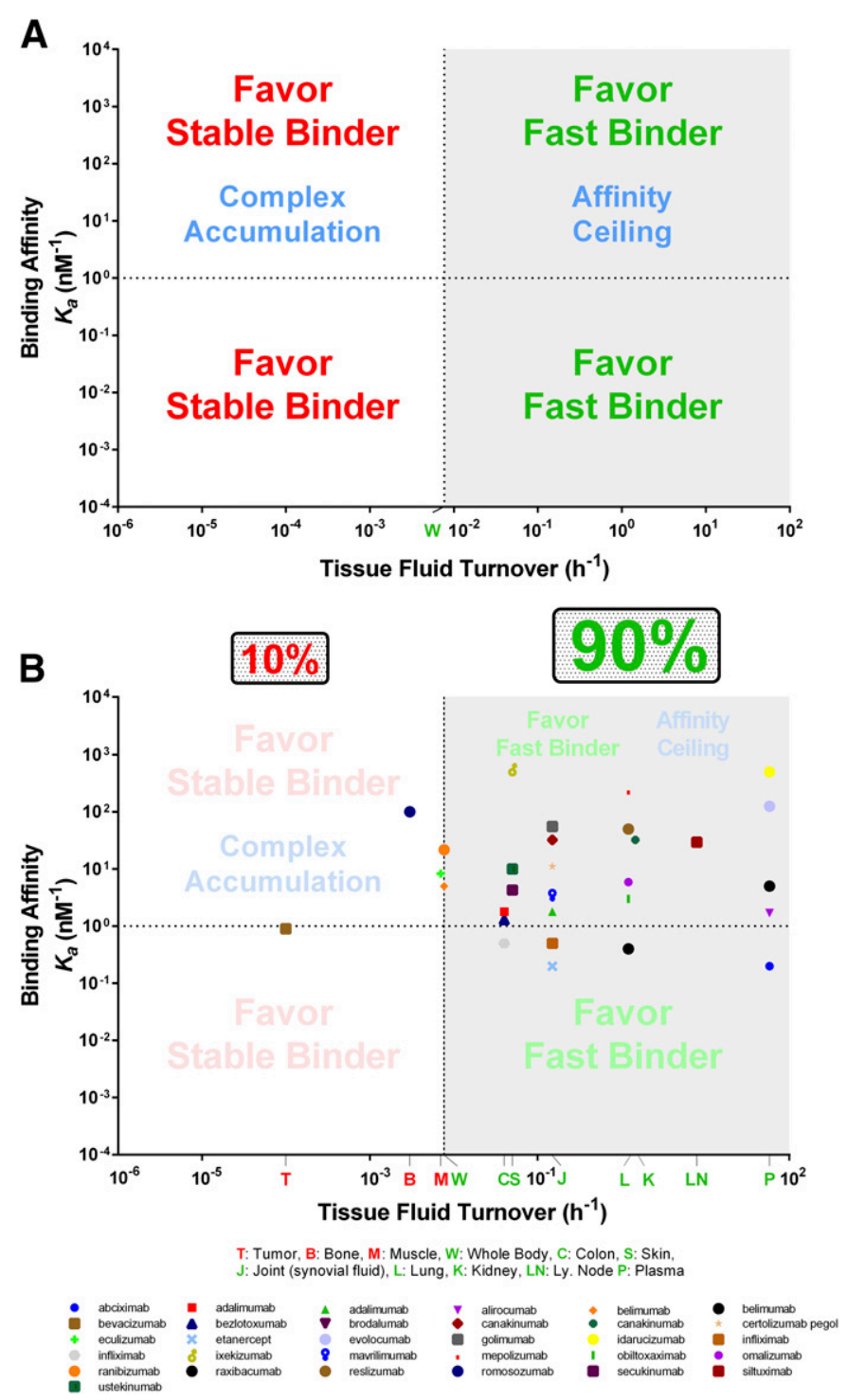

Fig. 5. Four scenarios proposed based on the binding affinity $\left(K_{\mathrm{a}},=k_{\mathrm{on}} / k_{\mathrm{off}}\right)$ and tissue fluid turnover rate. (A) For tissues with low fluid turnover, stable binders are generally favored but high affinity often confers increased accumulation of antibody-target complex; for tissues with high fluid turnover, fast binders are generally favored but lowering $k_{\text {off }}$ beyond fluid turnover rate produces a plateau effect. (B) Summary of 27 licensed antibodies that bind to soluble ligands for treatment of various diseases. Of these, 24 were approved for treatment of diseases that are associated with tissues with relatively high fluid turnover.

Optimization of target binding kinetics to achieve greater binding affinity is the first priority in developing biologics. However, as shown in our analysis, excessive pursuit of high binding affinity is not desirable and even wasteful (Rudnick et al., 2011); selection of sufficient binding affinity while particularly focusing on appropriate binding constants for a given diseased tissue is a rational approach. In surveying the 27 approved biologics with soluble targets, over $90 \%$ of the biologics treat diseases associated with tissues having fluid turnover rates higher than the system average. Three exceptions are bevacizumab, romosozumab, and eculizumab. Bevacizumab is an antibody targeting vascular endothelial growth factor, a proangiogenic cytokine used in treatment of multiple types of cancer (colon cancer, lung cancer, glioblastoma, and renal-cell carcinoma). In solid tumors that are generally believed to have low functional lymphatics, bevacizumab-vascular endothelial growth factor complexes are expected to accumulate with lesser therapeutic efficacy (Couzin-Frankel and Ogale, 2011; Van Cutsem et al., 2011; Khasraw et al., 2014). For tissues with relatively slow fluid turnover, strategies to increase lymph flow or enhance local degradation of the drug-target complexes might improve target suppression and efficacy.

Our mPBPK model was used to assess the influence of tissue fluid turnover rate on target suppression for biologics bound to soluble antigens. The simulations help explain why etanercept has limited efficacy in CD. For biologics that bind to soluble antigens in tissues, the interrelationships between target binding constants and tissue fluid turnover rates were also explored, showing that accumulation of drug-target complexes in tissues with slow fluid turnover can restrict the magnitude of target suppression. For tissues with high fluid turnover, a plateau effect was suggested for biologics with low target dissociation rates. These findings may help to prioritize strategies in the development of therapeutic antibodies for various diseases.

\section{Acknowledgments}

We thank Dr. Can Liu and Dr. Dongfen Yuan for providing assistance.

\section{Authorship Contributions}

Participated in research design: Li, Jusko, Cao.

Conducted experiments: $\mathrm{Li}$, Cao.

Performed data analysis: $\mathrm{Li}$, Cao.

Wrote or contributed to the writing of the manuscript: Li, Jusko, Cao.

\section{References}

Aaltonen KJ, Virkki LM, Malmivaara A, Konttinen YT, Nordström DC, and Blom M (2012) Systematic review and meta-analysis of the efficacy and safety of existing TNF blocking agents in treatment of rheumatoid arthritis. PLoS One 7:e30275.

Amini-Vaughan ZJ, Martinez-Moczygemba M, and Huston DP (2012) Therapeutic strategies for harnessing human eosinophils in allergic inflammation, hypereosinophilic disorders, and cancer. Curr Allergy Asthma Rep 12:402-412.

Bang LM and Keating GM (2004) Adalimumab: a review of its use in rheumatoid arthritis. BioDrugs 18:121-139.

Bauer W, Short CL, and Bennett GA (1933) The manner of removal of proteins from normal joints. J Exp Med 57:419-433.

Becker F, Potepalov S, Shehzahdi R, Bernas M, Witte M, Abreo F, Traylor J, Orr WA, Tsunoda I, and Alexander JS (2015) Downregulation of Foxc2 increased susceptibility to experimental colitis: influence of lymphatic drainage function? Inflamm Bowel Dis 21:1282-1296.

Beerli RR, Bauer M, Fritzer A, Rosen LB, Buser RB, Hanner M, Maudrich M, Nebenfuehr M, Toepfer JA, Mangold S, et al. (2014) Mining the human autoantibody repertoire: isolation of potent IL17A-neutralizing monoclonal antibodies from a patient with thymoma. MAbs 6:1608-1620.

Brown TJ, Laurent UB, and Fraser JR (1991) Turnover of hyaluronan in synovial joints: elimination of labelled hyaluronan from the knee joint of the rabbit. Exp Physiol 76:125-134.

Cantini F, Niccoli L, and Goletti D (2014) Adalimumab, etanercept, infliximab, and the risk of tuberculosis: data from clinical trials, national registries, and postmarketing surveillance. J Rheumatol Suppl 91:47-55.

Cao Y, Balthasar JP, and Jusko WJ (2013) Second-generation minimal physiologicallybased pharmacokinetic model for monoclonal antibodies. J Pharmacokinet Pharmacodyn 40:597-607.

Cao Y and Jusko WJ (2014a) Incorporating target-mediated drug disposition in a minimal physiologically-based pharmacokinetic model for monoclonal antibodies. $J$ Pharmacokinet Pharmacodyn 41:375-387.

Cao Y and Jusko WJ (2014b) Survey of monoclonal antibody disposition in man utilizing a minimal physiologically-based pharmacokinetic model. $J$ Pharmacokinet Pharmacodyn 41:571-580.

Carter PJ (2006) Potent antibody therapeutics by design. Nat Rev Immunol 6: 343-357.

Chen X, DuBois DC, Almon RR, and Jusko WJ (2017) Interrelationships between infliximab and recombinant tumor necrosis factor- $\alpha$ in plasma using minimal physiologically based pharmacokinetic models. Drug Metab Dispos 45:790-797.

Chen X, Jiang X, Jusko WJ, Zhou H, and Wang W (2016) Minimal physiologicallybased pharmacokinetic (mPBPK) model for a monoclonal antibody against interleukin-6 
in mice with collagen-induced arthritis. $J$ Pharmacokinet Pharmacodyn 43 : 291-304.

Chouinard L, Felx M, Mellal N, Varela A, Mann P, Jolette J, Samadfam R, Smith SY, Locher K, Buntich S, et al. (2016) Carcinogenicity risk assessment of romosozumab: a review of scientific weight-of-evidence and findings in a rat lifetime pharmacology study. Regul Toxicol Pharmacol 81:212-222.

Couzin-Frankel J and Ogale Y (2011) FDA. Once on 'fast track,' avastin now derailed. Science 333:143-144

Davies B and Morris T (1993) Physiological parameters in laboratory animals and humans. Pharm Res 10:1093-1095.

Deisseroth A, Ko CW, Nie L, Zirkelbach JF, Zhao L, Bullock J, Mehrotra N, Del Valle P, Saber H, Sheth C, et al. (2015) FDA approval: siltuximab for the treatment of patients with multicentric Castleman disease. Clin Cancer Res 21 950-954.

De Luca C and Trifonova A (2017) Patent disclosure requirements for therapeutic antibody patents. Expert Opin Ther Pat 27:867-875.

Eigenmann MJ, Karlsen TV, Krippendorff BF, Tenstad O, Fronton L, Otteneder MB, and Wiig $\mathrm{H}$ (2017) Interstitial IgG antibody pharmacokinetics assessed by combined in vivo- and physiologically-based pharmacokinetic modelling approaches. J Physiol 595:7311-7330.

Eikelboom JW, Quinlan DJ, van Ryn J, and Weitz JI (2015) Idarucizumab: the antidote for reversal of dabigatran. Circulation 132:2412-2422.

Fallahi-Sichani M, Flynn JL, Linderman JJ, and Kirschner DE (2012) Differential risk of tuberculosis reactivation among anti-TNF therapies is due to drug binding kinetics and permeability. $J$ Immunol 188:3169-3178.

Feldmann M, Brennan FM, and Maini RN (1996) Role of cytokines in rheumatoid arthritis. Annu Rev Immunol 14:397-440.

Garg A and Balthasar JP (2007) Physiologically-based pharmacokinetic (PBPK) model to predict IgG tissue kinetics in wild-type and FcRn-knockout mice. J Pharmacokinet Pharmacodyn 34:687-709.

Garrison L and McDonnell ND (1999) Etanercept: therapeutic use in patients with rheumatoid arthritis. Ann Rheum Dis 58 (Suppl 1):I65-I69.

Gibbs JP, Doshi S, Kuchimanchi M, Grover A, Emery MG, Dodds MG, Gibbs MA, Somaratne R, Wasserman SM, and Blom D (2017) Impact of target-mediated elimination on the dose and regimen of evolocumab, a human monoclonal antibody against proprotein convertase subtilisin/kexin type 9 (PCSK9). J Clin Pharmacol 57:616-626.

Greig SL (2016) Brodalumab: first global approval. Drugs 76:1403-1412.

Guo R, Zhou Q, Proulx ST, Wood R, Ji RC, Ritchlin CT, Pytowski B, Zhu Z, Wang YJ, Schwarz EM, et al. (2009) Inhibition of lymphangiogenesis and lymphatic drainage via vascular endothelial growth factor receptor 3 blockade increases the severity of inflammation in a mouse model of chronic inflammatory arthritis. Arthritis Rheum 60:2666-2676.

Hart TK, Cook RM, Zia-Amirhosseini P, Minthorn E, Sellers TS, Maleeff BE, Eustis S, Schwartz LW, Tsui P, Appelbaum ER, et al. (2001) Preclinical efficacy and safety of mepolizumab (SB-240563), a humanized monoclonal antibody to IL-5, in cynomolgus monkeys. J Allergy Clin Immunol 108:250-257.

Hernandez LD, Racine F, Xiao L, DiNunzio E, Hairston N, Sheth PR, Murgolo NJ, and Therien AG (2015) Broad coverage of genetically diverse strains of Clostridium difficile by actoxumab and bezlotoxumab predicted by in vitro neutralization and epitope modeling. Antimicrob Agents Chemother 59:1052-1060.

Horiuchi T, Mitoma H, Harashima S, Tsukamoto H, and Shimoda T (2010) Transmembrane TNF- $\alpha$ : structure, function and interaction with anti-TNF agents. Rheumatology (Oxford) 49:1215-1228.

Khasraw M, Ameratunga MS, Grant R, Wheeler H, and Pavlakis N (2014) Antiangiogenic therapy for high-grade glioma. Cochrane Database Syst Rev 9: CD008218.

Kim MS, Lee SH, Song MY, Yoo TH, Lee BK, and Kim YS (2007) Comparative analyses of complex formation and binding sites between human tumor necrosis factor-alpha and its three antagonists elucidate their different neutralizing mechanisms. $J \mathrm{Mol}$ Biol 374:1374-1388.

Levick JR (1998) A method for estimating macromolecular reflection by human synovium, using measurements of intra-articular half lives. Ann Rheum Dis $\mathbf{5 7}$ 339-344.

Lindena J, Küpper W, and Trautschold I (1986) Catalytic enzyme activity concentration in thoracic duct, liver, and intestinal lymph of the dog, the rabbit, the rat and the mouse. Approach to a quantitative diagnostic enzymology, II. Communication. $J$ Clin Chem Clin Biochem 24:19-33.

Liu L, Lu J, Allan BW, Tang Y, Tetreault J, Chow CK, Barmettler B, Nelson J, Bina $H$, Huang L, et al. (2016) Generation and characterization of ixekizumab, a humanized monoclonal antibody that neutralizes interleukin-17A. J Inflamm Res $\mathbf{9}$ $39-50$.

Markham A and Lamb HM (2000) Infliximab: a review of its use in the management of rheumatoid arthritis. Drugs 59:1341-1359.

Mazumdar S (2009) Raxibacumab. MAbs 1:531-538.

Nagy CF, Mondick J, Serbina N, Casey LS, Carpenter SE, French J, and Guttendorf R (2017) Animal-to-human dose translation of obiltoxaximab for treatment of inhalational anthrax under the US FDA animal rule. Clin Transl Sci 10:12-19.
Olesen CM, Coskun M, Peyrin-Biroulet L, and Nielsen OH (2016) Mechanisms behind efficacy of tumor necrosis factor inhibitors in inflammatory bowel diseases. Pharmacol Ther 159:110-119.

Patel AM and Moreland LW (2010) Certolizumab pegol: a new biologic targeting rheumatoid arthritis. Expert Rev Clin Immunol 6:855-866.

Pizarro TT and Cominelli F (2007) Cytokine therapy for Crohn's disease: advances in translational research. Annu Rev Med 58:433-444.

Platania CBM, Di Paola L, Leggio GM, Romano GL, Drago F, Salomone S, and Bucolo C (2015) Molecular features of interaction between VEGFA and antiangiogenic drugs used in retinal diseases: a computational approach. Front Pharmacol 6:248.

Poirier S and Mayer G (2013) The biology of PCSK9 from the endoplasmic reticulum to lysosomes: new and emerging therapeutics to control low-density lipoprotein cholesterol. Drug Des Devel Ther 7:1135-1148.

Renkin EM and Wiig H (1994) Limits to steady-state lymph flow rates derived from plasma-to-tissue uptake measurements. Microvasc Res 47:318-328.

Rondeau JM, Ramage P, Zurini M, and Gram H (2015) The molecular mode of action and species specificity of canakinumab, a human monoclonal antibody neutralizing IL-1 $\beta$. MAbs 7:1151-1160.

Rother RP, Rollins SA, Mojcik CF, Brodsky RA, and Bell L (2007) Discovery and development of the complement inhibitor eculizumab for the treatment of paroxysmal nocturnal hemoglobinuria. Nat Biotechnol 25:1256-1264.

Rudnick SI, Lou J, Shaller CC, Tang Y, Klein-Szanto AJ, Weiner LM, Marks JD, and Adams GP (2011) Influence of affinity and antigen internalization on the uptake and penetration of Anti-HER2 antibodies in solid tumors. Cancer Res $\mathbf{7 1}$ : $2250-2259$

Scallon B, Cai A, Solowski N, Rosenberg A, Song XY, Shealy D, and Wagner C (2002) Binding and functional comparisons of two types of tumor necrosis factor antagonists. J Pharmacol Exp Ther 301:418-426.

Shah DK and Betts AM (2012) Towards a platform PBPK model to characterize the plasma and tissue disposition of monoclonal antibodies in preclinical species and human. J Pharmacokinet Pharmacodyn 39:67-86.

Shealy DJ, Cai A, Staquet K, Baker A, Lacy ER, Johns L, Vafa O, Gunn G III, Tam S, Sague $S$, et al. (2010) Characterization of golimumab, a human monoclonal antibody specific for human tumor necrosis factor $\alpha$. MAbs 2:428-439.

Song MY, Park SK, Kim CS, Yoo TH, Kim B, Kim MS, Kim YS, Kwag WJ, Lee BK, and Baek K (2008) Characterization of a novel anti-human TNF- $\alpha$ murine monoclonal antibody with high binding affinity and neutralizing activity. Exp Mol Med 40:35-42.

Stein AM and Ramakrishna R (2017) AFIR: a dimensionless potency metric for characterizing the activity of monoclonal antibodies. CPT Pharmacometrics Syst Pharmacol 6:258-266.

Tiwari A, Abraham AK, Harrold JM, Zutshi A, and Singh P (2017) Optimal affinity of a monoclonal antibody: guiding principles using mechanistic modeling. AAPS J 19:510-519.

Tracey D, Klareskog L, Sasso EH, Salfeld JG, and Tak PP (2008) Tumor necrosis factor antagonist mechanisms of action: a comprehensive review. Pharmacol Ther 117:244-279.

Van Cutsem E, Lambrechts D, Prenen H, Jain RK, and Carmeliet P (2011) Lessons from the adjuvant bevacizumab trial on colon cancer: what next? J Clin Oncol 29:1-4. van Schouwenburg PA, Rispens T, and Wolbink GJ (2013) Immunogenicity of antiTNF biologic therapies for rheumatoid arthritis. Nat Rev Rheumatol 9:164-172.

Wang B, Wu CY, Jin D, Vicini P, and Roskos L (2018) Model-based discovery and development of biopharmaceuticals: a case study of mavrilimumab. CPT Pharmacometrics Syst Pharmacol 7:5-15.

Wang W, McIntosh TS, Jiang X, Doddareddy R, Dell EC, and Zhou H (2016) Deciphering the in vivo performance of a monoclonal antibody to neutralize its soluble target at the site of action in a mouse collagen-induced arthritis model. Pharm Res 33:1040-1049.

Wang W, Wang EQ, and Balthasar JP (2008) Monoclonal antibody pharmacokinetics and pharmacodynamics. Clin Pharmacol Ther 84:548-558.

Wiig H, Kaysen GA, al-Bander HA, De Carlo M, Sibley L, and Renkin EM (1994) Interstitial exclusion of IgG in rat tissues estimated by continuous infusion. Am J Physiol 266:H212-H219.

Wiig $\mathrm{H}$ and Tenstad $\mathrm{O}$ (2001) Interstitial exclusion of positively and negatively charged IgG in rat skin and muscle. Am J Physiol Heart Circ Physiol 280:H1505-H1512.

Zhou H and Theil FP (2015) ADME and translational pharmacokinetics/ pharmacodynamics of therapeutic proteins. Gut 60:774-779.

Zhou Q, Guo R, Wood R, Boyce BF, Liang Q, Wang YJ, Schwarz EM, and Xing L (2011) Vascular endothelial growth factor C attenuates joint damage in chronic inflammatory arthritis by accelerating local lymphatic drainage in mice. Arthritis Rheum 63:2318-2328.

Address correspondence to: Yanguang Cao, Division of Pharmacotherapy and Experimental Therapeutics, 2318 Kerr Hall, UNC Eshelman School of Pharmacy, University of North Carolina at Chapel Hill, Chapel Hill, NC 27599-7569. E-mail: yanguang@unc.edu 